\title{
EGFR Inhibitor ABBV-221
}

National Cancer Institute

\section{Source}

National Cancer Institute. EGFR Inhibitor ABBV-221. NCI Thesaurus. Code C120556.

An intravenously-administered agent inhibitor of the epidermal growth factor receptor (EGFR), with potential antineoplastic activity. Upon administration, ABBV-221 binds to and inhibits the activity of EGFR. This prevents EGFR-mediated signaling and may induce cell death in EGFR-expressing tumor cells. EGFR, a receptor tyrosine kinase mutated in many tumor cell types, plays a key role in tumor cell proliferation and tumor vascularization. 